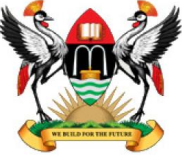

East African School of

Higher Education Studies \& Development
Makerere Journal of Higher Education

ISSN: 1816-6822; 5 (1) (2013) 3 ï 21

DOI: http://dx.doi.org/10.4314/majohe.v5i1.1

(C) The Author(s) 2013

Reprints \& permission: EASHESD

http://ajol.info/majohe

\title{
Integration of ICT into Teacher Training and Professional Development in Kenya
}

\author{
Truphena E. Mukuna ${ }^{1}$ \\ ${ }^{1}$ School of Education, Maasai Mara University [E-mail: turumukuna@yahoo.com]
}

\begin{abstract}
Teachers can only effectively integrate technology in their instruction if they are themselves knowledgeable about the technology. In Kenya, integration of ICT into the curriculum has been the subject of extensive research and various researches have reported challenges encumbering integration: resistance of teachers to embrace innovation; lack of infrastructure for ICT integration; negative attitudes of teachers towards integrating ICT; and school management related problems. These challenges beg several questions: What is missing in the teacher education and training curriculum? Is there skill training and maintenance for teachers? Do the teacher training institutions have the necessary infrastructure for ICT integration? This paper reports on the findings of a study that attempted to respond to these questions.
\end{abstract}

Keywords: ICT; Curriculum innovation; Teacher education.

\section{$1 \quad$ Introduction}

UNESCOâs planning guide for Information and Communication Technology (ICT) in teacher education cites three key principles for effective ICT development in teacher education that were put forward by the Society for Information Technology and Teacher Education (SITE, 2002).These were; to infuse technology into the entire teacher education programme, technology should be introduced in context, and that students should experience innovative technology supported learning environment in their teacher education programmes. The teaching profession needs to migrate from a teacher-centred lecture based instruction to a learner-centred interactive learning environment. To attain this aspiration, an ICT enabled teacher education is fundamental. There is an urgent need to equip African teachers with ICT skills so as to develop their learners as critical citizens in a digital world. 
With the emerging new technologies, the teaching profession is evolving from an emphasis on teacher-centred, lecture-based instruction to student centred, interactive learning environments. Research shows that technology only provides raw materials for enhanced educational strategies. Meaningful technology integration into pedagogy depends on how teachers plan for and use it in the classroom for effective instructional delivery. Technology is a channel for helping teachers to communicate better with their learners. Teachers can use technology in their classrooms when they are first and foremost informed and knowledgeable as stated above. Technology is only a tool to help teachers overcome obstacles that impede effective teaching and learning. The teacherôs role is to ensure use of technology-based methods in both learning theory and teaching practice. The technology use should match specific teaching and learning needs. The teacher needs to use technology in more innovative ways to make his/her teaching better and enforce parent-teacher collaboration in curriculum development.

Research shows that technology only provides raw materials for enhanced educational strategies; meaningful technology integration into pedagogy depends on how teachers plan for and use it in the classroom for effective instructional delivery. Technology is a channel for helping teachers communicate better with the learners (Doering \& Robleyer, 2007). It can make teaching better but not make bad teaching good. The teacher needs a wealth of knowledge on technology so that he shapes the future of his/her learners. Each teacher should use technology to articulate the vision of education by acquiring skills to help toward realizing the vision. The technology use should match specific teaching and learning needs. There should be informed use; teachers should also know the technological pedagogical and content knowledge (TPACK) thus knowledge of content and teaching strategies including technological knowledge.

There are various technological resources at the disposal of teachers to use. All the integration strategies require both the hardware (equipment) and software (programmes). The software to support pedagogical and content knowledge is divided into three;

- Instructionalð programmes designed to teach skills or information through demonstrating examples, explanations or problem-solving.

- Productivityð Programmes designed to help teachers and students to plan, develop materials and keep progress records.

- Administrativeð Programmes administrators at school, county, nation, district or province use to support record keeping and exchange of information among various stakeholders.

The hardware includes computer laboratories, work stations, laptops, desktops, mobile phones, radios, calculators, projectors and video recorders. The software 
includes desktop publishing, word processing, email, power point, chat room, drills, videos, simulations, instructional games, internet, instructional software and multi-media.

Over the last decade, many countries that included ICTs in education were slow to also include it in teacher education. Only recently have national agencies begun to realize the importance of educating teachers at the beginning of their careers. Younger people are more likely to be familiar with ICTs, to be adaptable, and to not yet have formed habitual modes of instruction that are more difficult to change with more experienced teachers. It is in the pre-service stage that they are most open to learning how to infuse technology into instruction. Based on their long experiences with traditional modes of learning, teacher educators may find it challenging to incorporate ICTs into their own instructional practices. They may also lack experience in developing the complex partnerships between higher education and schools that facilitate technology- rich contexts for training student teachers.

Designing and implementing successful ICT-enabled teacher education programmes is the key to fundamental, wide-ranging educational reforms necessary for the realization of Vision 2030. Teacher education institutions may either assume a leadership role in the transformation of education or be left behind in the swirl of rapid technological change. For education to reap the full benefits of ICTs in learning, it is essential that pre- and in-service teachers are able to effectively use these new tools for learning. Teacher education institutions and programmes must provide the leadership for pre- and in-service teachers and model the new pedagogies and tools for learning. To accomplish these goals, teacher education institutions must work closely and effectively with administrators, national or state educational agencies, teacher unions, business and community organizations, politicians and other important stakeholders in the educational system. Teacher training institutions also need to develop strategies and plans to enhance the teaching-learning process within teacher education programmes and to assure that all future teachers are well prepared to integrate ICTs in their classrooms for teaching and learning.

As Kenya moves towards vision 2030 considering the pressure to move with the times of this information and digital era, the school curriculum should be made relevant and useful to the needs of the learners. Several questions must be put into consideration such as are teachersô views included? Are teachers involved right from the planning stage? Have needs assessments in various subject areas been done? Have these ideas been incorporated in the in-service and pre-service training? Have teachers been inducted to do internal instructional supervision? How do teachers receive the innovation? What is expected of them? What is missing in the teacher training curriculum? Is there skill maintenance training for teachers? Do schools have necessary 
infrastructure for practice, e.g. Electricity, policies, software and hardware, finances?

In Kenya today, there is an upsurge of primary teacher training colleges and universities. Due to these increased numbers, there is a strain on available resources. Some of these universities and teacher training colleges do not have learning resource centres let alone a well equipped library. This poses a great challenge to these teacher training institutions to link theory and practice. Many pre-service teachers in the TTCs end up not doing educational media practicals which would otherwise equip them with knowledge and skills on integration of ICTs in the classroom. The end result is teachers who are technologically incompetent. The little or no levels of interaction with technology during their pre-service training culminate into resistance to integrate ICTs in classrooms.

Another challenge confronting our educational systems is how to transform the curriculum and teaching-learning process to provide students with the skills to function effectively in this dynamic, information-rich, and continuously changing environment. Education is at the confluence of powerful and rapidly shifting educational, technological and political forces that will shape the structure of educational systems across the globe for the remainder of this century. Many countries are engaged in a number of efforts to effect changes in the teaching/ learning process to prepare students for information and technology based society. There is an urgent need to reconsider the curriculum content, design, implementation strategies and evaluation procedures in Kenya.

There have been several curriculum changes in Kenya in the past that take so long to be implemented. The main reason most researchers give is resistance by teachers to implement the new curriculum. In most researches, incompetence of teachers and lack of training prior to introduction of the new curriculum have been cited. Most studies have focused on methods of teaching, overload of the curriculum, scope, sequence/and overlaps, content, teachersôattitudes towards the subjects, teaching and learning materials, but not on the teacher as the implementer of the curriculum. The role of the teacher in the changed curriculum is very critical to say the least; it is the engine of the curriculum change. How the teacher understands the curriculum change, owns it and implements it is dependent on how much knowledge he/she has on the curriculum change. It depends on the characteristics of the innovation, context and content (Fullan, 1992; Otunga et al, 2011). The objectives, practicality, simplicity, or complexity, adaptability of curriculum must be put in perspective. The teacher needs to understand why the change and how it will benefit him/her and the learners. S/he must understand how s/he is expected to fit the changes in his lessons (Ornstein \& Hunkins, 2004).

A good curriculum is invalid without quality teachers to implement it. We should go beyond the assumption that teachers know it all and will somehow find their ways around. We should not assume that teachersô knowledge 
doesnâ need renewal. If continuous professional development (CPD) is done, we believe that teachers will not only embrace the curriculum changes and institutionalize them but will do their best. If they are taught the ñhowòand are mentored or supervised using clinical supervision, then Kenya Institute of Curriculum Development would have achieved its aim of transforming the curriculum to meet the needs of Vision 2030.It follows that the pre-service curriculum needs to be overhauled; the Policy on Teaching Practice in colleges and universities needs to be re-drawn to fill the gaps. The Lecturers and other instructional supervisors also need CPD to understand the curriculum changes so that Monitoring and Evaluation of the same is effective.

This paper argues that teachers in Kenya should have technological, pedagogical and content knowledge for them to effectively use ICTs in their classrooms. It goes further to offer guidance on how teacher training in Kenya can not only offer technological and pedagogical skill training but maintain it through continuous professional development of teachers, administrators and technicians. The paper further proposes a framework for ICTs in teacher education, describes the essential conditions that must be met for successful technology integration and provides guidelines for the development of a strategic planning process. It also identifies important strategies for managing the change process in the teacher education programme as technology becomes a catalyst for transforming the teaching-learning process.

\section{Essential Conditions for Technology Integration}

Integration of ICTs into pedagogical practices needs the following conditions. These conditions were summarized by ISTEs NETS for Teachers (2008). These include:

1. A shared vision for technology integration. This vision should be shared by the school, district, county and nation at large. Educational leaders must view ICTs as a core value. The planning for integration of ICTs into the curriculum should involve all the stakeholders who are parents, community leaders, school management committees, district and county teachers. There is need to increase the technology budget; and teachers should be trained in integrating ICTs into the classroom and linking technology to curriculum needs.

2. Empowered leaders: stakeholders at all levels must be informed about the goals of the community, district, county and school.

3. Standards and curriculum support: the content area and technology should be assigned to complement each other. 
4. Required Policies $\ddot{i}$ there need to be policies that ensure appropriate behaviour, safety, equitable treatment of all students, financial assistance incentives and accountability.

5. Access to hardware, software and other resources for sustainable integration.

6. Skilled personnel and opportunities for professional development $\ddot{i}$ preservice training should have a component of integration of ICTs into the classroom practices. However, since technology keeps changing continuing staff development is an essential condition for effective technology integration. Schools must have a plan for CPD for teachers, administrators, technicians, etc not only to learn the latest technology, but more importantly the most effective pedagogy related to integrating the technology into the classroom.

7. Technical assistance: technical support and maintenance for students and teachers is crucial.

8. Appropriate teaching and assessment approaches.

9. Engaged communities: partnerships and collaborations.

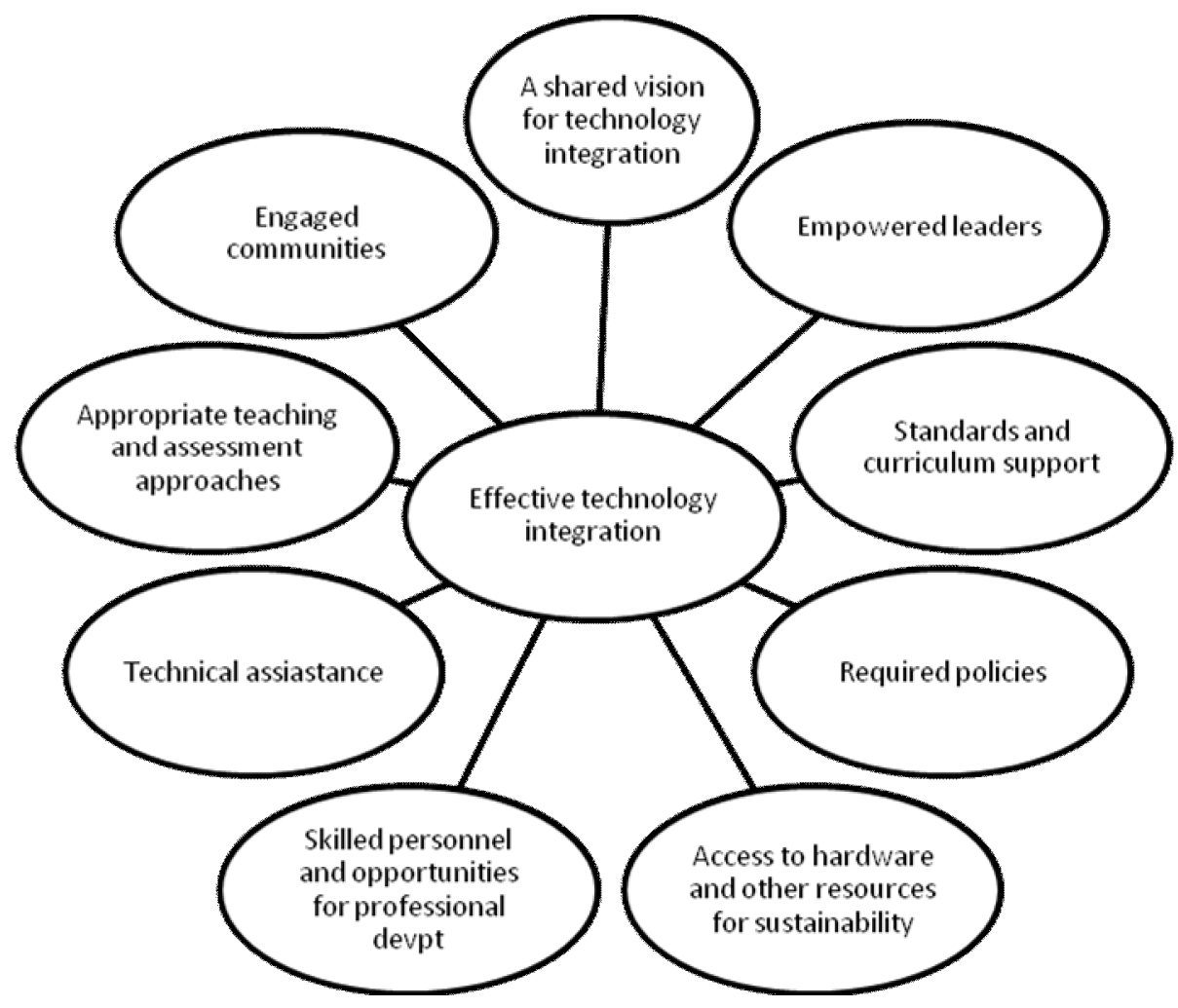

Figure 1: Effective Technology Integration 


\section{Stages of Professional Development of Teachers in ICTs}

It will not be surprising to find computers in classrooms collecting dust; computer labs locked because there is no one trained to run them or pupils playing non-educational games on computers for hours on end. The Jubilee government has set aside millions of shillings this year to be spent on buying laptops for every child entering class one in 2014. Much of this money will most likely be wasted because teachers are not trained to use technology effectively. Educational technology is not, and never will be, transformative on its own $\ddot{i}$ it requires teachers who can integrate technology into the curriculum and use it to improve student learning. In other words, computers cannot replace teachers. Teachers are the key to whether technology is used appropriately and effectively. That said, designing and implementing successful teacher professional development programs in the application of technology is neither easy nor inexpensive. The leadership of this country have a very noble idea but they have failed to allocate funds for training teachers, school management and technicians on integration of ICTs into the classroom. Making Kenya digital by 2030 may become a pipe dream if there is no constant revision of teacher professional development programs related to technology.

Teachers remain the gatekeepers for studentsô access to educational opportunities afforded by technology: they cannot and should not be ignored. Providing technical skills training to teachers in the use of technology is not enough. Teachers also need professional development in the pedagogical application of those skills to improve teaching and learning. Traditional onetime teacher training workshops have not been effective in helping teachers to feel comfortable using technology or to successfully integrate it into their teaching. Instead, a new paradigm is emerging that replaces training with lifelong professional preparedness and development of teachers. This approach includes pre-service and in-service training, as well as ongoing pedagogical and technical support and mentoring.

While technology increases teachersôtraining and professional development needs, it also offers part of the solution. Information and communication technologies (ICTs) can improve pre-service teacher training, by providing access to more and better educational resources, offering multimedia simulations of good teaching practice, catalyzing teacher-to trainee collaboration, and increasing productivity of non instructional tasks. ICTs can also enable in-service teacher professional development at a distance, collaborative learning, and individualized training opportunities. Finally, ICTs can overcome teachersô isolation, breaking down their classroom walls and connecting them to colleagues, mentors, curriculum experts and the global teacher community on a continuous basis. 
Approaches to the professional development of teachers must be dependent on context and culture. Since there are a variety of approaches, an overview of the many stages in which teachers receive teacher education may prove helpful. Professional development to incorporate ICTs into teaching and learning is an ongoing process and should not be thought of as one 'injectionô of training. Teachers need to update their knowledge and skills as the school curriculum and technologies change. Individuals develop in stages and mature over time. Personal development must be accompanied by organizational development in schools, training centres, and universities.

In many regions, teachers engage in preparation before they start teaching in schools, a stage referred to in this paper as pre-service teacher education. When pre-service teachers begin to teach, they may be given additional support to handle the complexity of their work for the first to third years of their career. This stage of professional development is called induction. The induction stage demands a great deal of effort and commitment, and research in developed countries reveals that around $30 \%$ of teachers may drop out during this time. Some teachers do not have the benefit of a preparatory course and must learn while teaching in schools, a condition referred to as on-the-job training. Such training is probably carried out within the school, perhaps with the teacher receiving some release from normal duties.

Teachers and teacher educators develop ICT competence in stages. Those who are fluent with technology may not appreciate how difficult it is for technology novices to appropriate ICTs into their professional practice. Teacher educators often find this task even more difficult than teachers do, because they typically have higher levels of content and pedagogical expertise that must be respected. Teacher educators, because they have to work in multiple contextsboth the home institution and the field where students are placed to observe and practice teaching-may also be more influenced by the absence of the essential conditions for ICTs in teacher education

Four stages are common, but they may be repeated with new forms of ICTs or applications of ICTs to new areas. The first stage for each individual is awareness, and the appropriate response at this stage is to provide information about a relevant application of ICTs and appropriate ways that it may be used in the individualôs current professional or personal concerns. Please note the learner-centred nature of this approach; the concerns are not those of the supporter (the ICT expert) or the organization, but of the individual teacher educator. Teacher educators then explore the use of the application. They need support to put this ICT application into practice in a timely manner and to reflect on its effectiveness. Only after teacher educators have gone through these stages are they able to adapt their practice to make better use of ICTs, and then move toward the final stage to become innovators and modellers of excellent practice for their students and colleagues. 
The advent of ICTs provides the opportunity to engage in this process from a new perspective and to model processes of learning for colleagues and students. It is acceptable for teacher educators to adopt only those aspects of ICTs that are relevant to their practice, but they must first be allowed to explore the range of possibilities, so that they and their students may become critically aware of, and competent in, diverse ICT applications. Of course, any teacher educators continually strive to be responsive to developments and innovations in education within and beyond their discipline.

To understand the strategies of professional development it is important to understand how they are embedded in the broader context of the planning and implementation of ICTs in teacher education. Teacher educators need to develop competence in the core themes of: pedagogy, collaboration and networking, technical competence, and social issues. This needs to be done within the local and global cultural contexts of: lifelong learning, leadership and vision, and planning and management of change.

Teacher education is an ongoing process of lifelong learning. The final stage, consisting of additional professional development, is called in-service teacher education. It is important to note that some very strong models of teacher education provide simultaneous professional development for more than one group. For example, pre-service preparation can be aligned with in-service teacher education. A practicing teacher may work with a pre-service teacher education student on an innovative educational project. This not only increases the research potential of the in-service teacher, but the pre-service teacher also experiences role modelling and, as a result, may have an easier transition into teaching.

Professional learning communities allow teachers to support the professional development of colleagues and receive support themselves. ICTs have increased the access to and reach of such professional associations. Mentorship can be fostered across geographic distances and supported by synchronous and asynchronous interaction. Professional development may also be enhanced by public or private partnerships with the community. Such partnerships may be particularly appropriate for professional development related to ICTs, with financial and technical support contributed by ICT companies, such as the Intel Teach to the Future Programme, or by local communities. The professional development of teacher educators is also essential. Unless teacher educators model effective use of technology in their own classes, it will not be possible to prepare a new generation of teachers who effectively use the new tools for learning. It is also important to consider the question of who may teach.

With ICTs, students often become teachers, using the processes of peer tutoring or reciprocal mentoring. Indeed, a teacher may facilitate learning by reversing the teaching-learning roles, with students acting as expert learners who model the learning process. ICTs provide extensive opportunities for this 
to occur in ways that can increase the self-esteem, motivation, and engagement of students. Teachers need encouragement to adopt such strategies rather than to feel ashamed to be taught by young learners. Members of the community also may become teachers, or at least invited experts. ICTs extend the range of such opportunities and provide access to extensive relevant supporting materials. The teacherôs role changes to manager and facilitator in many of these situations as the teacher helps the expert communicate with the learners and scaffolds the learning process. The teacher also acquires professional development by learning from the expert.

The focus of professional development should also be expanded to those who work with teachers: the classroom assistants, school leaders, and members of regional and national organizations for curriculum and professional development. A common vision for the role of ICTs in education is important for its success. Teachers may find it impossible to incorporate ICTs into their work without support and encouragement from colleagues, parents, and leaders. To bring this about, these community members may also need professional development, along with the teachers.

The most obvious technique for professional development for teachers is to provide courses in basic ICTs knowledge and skills, delivered by experts in the areas. These types of courses, taught at training centres or universities with a syllabus set by regional or national agencies, have been a common practice in many countries. However, this approach has had limited success without follow-on training and support, as compared to effective use of ICTs by trained teachers. Similarly, courses for teachers are difficult to implement in ways that result into application of ICTs in classroom instruction or other professional practices without additional support.

Teacher professional development in the use of technology should embody and model the forms of pedagogy that teachers can use themselves in their classrooms. As the need and demand for teacher professional development increases, the key challenges will be ensuring content quality, reliable and appropriate training delivery infrastructure, follow-up support, measurable outcomes, and all at acceptable cost. For example, these training programs should;

- Empower teachers to develop their knowledge and skills actively and experientially, in a variety of learning environments, both individual and collaborative.

- Include a variety of learning strategies, including direct instruction, deduction, discussion, drill and practice, induction and sharing.

- Aim at higher-order thinking skills.

- $\square$ Provide an authentic learning environment so that teachers engage in concrete tasks within realistic scenarios. 
- Emphasize ways that technology can facilitate and enhance teachersô professional lives.

- Encourage teachers to be mentors, tutors and guides of the studentsô learning process (rather than simple presenters of knowledge and information).

- Develop teachersô skills in learning how to learn (define learning objectives, plan and evaluate learning strategies, monitor progress and adjust as needed).

- Promote cooperative and collaborative learning.

- $\square \mathrm{Be}$ sensitive to the culture and diversity of teachers as learners, using a multifaceted approach so as to respond to different learning styles, opportunities, environments and starting points.

- Enable learning independent of time and place (anytime, anywhere learning).

A key for successful teacher professional development programs is a modular structure, corresponding to different levels of teacher expertise and experience using technology. Adapting materials to teachersô comfort level and starting points is essential. In this way, teachers new to technology can be exposed to the full series of professional development modules, while teachers higher up the learning curve can enter where their knowledge and skills stop, and help their less technology-savvy colleagues along. The basic principles of Adult Learning should be incorporated, meaning the training program is highly social and cooperative, with opportunities to share experiences and combine instruction with discussion, reflection, application and evaluation. In addition to these principles, technology enables an even more collaborative approach and maximizes peer-to-peer sharing of the challenges, frustrations, advantages and successes of using technology to teach and learn. Such an approach encourages the use of illuminating failures in the use of technology in the classroom, as well as examples of best practice. Finally, these principles of teacher professional development for technology imply the need to build community and systems of on-going support, from peers, mentors and experts. Single training events that leave teachers alone afterwards should be avoided.

\section{Content of Teacher Professional Development Programs in the Use of ICT}

What should be learned? What skills and attitudes do teachers need to develop? What knowledge do they need to construct in order to effectively use technology to improve teaching and learning? This topic has been extensively 
discussed over the last ten years as information technology, and particularly the Internet, has been introduced to schools around the world. To begin with, the designers of a teacher professional development program for use of technology need to determine current levels of teacher competency in this area. The International Society for Technology in Education (www.iste.org) has produced a set of standards for teacher skills and knowledge in the use of technology, which serves as a useful diagnostic tool to determine competency levels and basic content of teacher professional development programs. While no single set of standards ñfits allò and differing economic, social, cultural, educational, and technological realities require different approaches, some minimum guidelines and suggestions for the content of teacher professional development in the use of technology are warranted.

Policymakers should assume as a bare minimum requirement at least twentyfour (24) hours (three full days) of teacher training in the use of technology. This would include basic operating systems, word processing and spreadsheets. Obviously, the more time allocated for this, particularly hands-on time, the greater the mastery of these basic skills. Teachers should finish this basic course with at least the fundamentals necessary for them to practice and further develop their skills on their own back in their schools. Adding another sixteen (16) hours of training and Internet access would enable teachers to access information on the Internet, do some basic lesson planning integrating technology, and exchange e-mail messages and files with colleagues and experts. With this base of forty (40) hours of professional development, provided that the methodology of the course incorporates some of the key interactive learning principles described above, teachers should be able to begin using technology in the classroom.

Experience of the World Links program suggests that at least eighty (80) hours of professional development are required before teachers can really begin to integrate technology into their teaching. Additional content would include linking curricular objectives to technology-based activities, development of lesson plans and evaluation strategies that incorporate technology, construction of educational web sites, and discussion of ethical issues related to technology and education. Ideally, this would be provided in various stages, allowing time for teachers to experiment with and apply their new technological skills and knowledge in the classroom before moving on to more advanced applications. This approach also allows teachers to reflect upon and share their learning experience (both positive and negative) with their peers, promoting the social construction of knowledge.

World Links has been one of the pioneers in developing and delivering teacher professional development programs in the use of technology to improve teaching and learning in developing countries. It is by no means the ñdefinitiveò program nor the most easily replicated and scaled. However, for purposes of 
illustration, the complete World Links Teacher Professional Development program includes two hundred (200) hours of training, equivalent to five 40hour weeks. This takes teachers with no prior contact with a computer to full competency, over a two- to three- year period.

\section{$5 \quad$ Motivation and Incentives}

A key issue that must be addressed in Kenya is teacher motivation to participate in professional development workshops in the use of technology. While socalled ñchampion teachersò will request and seek out professional development opportunities in the use of technology, the vast majority of teachers will not. Teachers are generally reluctant to change their teaching styles and habits, are cautious of time-consuming activities that may take away from other highpriority obligations (economic, familial or educational), have difficulty in seeing the potential pay-off beforehand of this kind of training, and may feel genuinely threatened by technology such that they want to distance themselves from it rather than embrace it. Incentives, both extrinsic and intrinsic, which could be used successfully to motivate teachers to participate in professional development ICT workshops, include the following: certification of training by Ministry of Education, public recognition and time allocation by supervisors, $\square$ reduced isolation and increased Professional Satisfaction, enhanced productivity and $\square$ opportunities to become a Trainer of Trainers.

Continuous Professional Development programmes should emphasize technology integration and interdisciplinary collaborative projects as the main topics for teacher training, and tie ICTs use to the development of basic skills in students. The teacher is responsible for establishing the classroom environment and preparing the learning opportunities that facilitate studentsô use of technology to learn, communicates, and develop knowledge products; consequently, it is critical that all classroom teachers are prepared to provide their students with these opportunities. Teacher preparation programmes must provide technology-rich experiences throughout all aspects of the training programmes.

Teachers must be prepared to empower students with the advantages technology can bring. Schools and classrooms, both real and virtual, must have teachers who are equipped with technology resources and skills and who can effectively teach the necessary subject matter content while incorporating technology concepts and skills. Real-world connections, primary source materials, and sophisticated data-gathering and analysis tools are only a few of the resources that allow teachers to provide heretofore unimaginable opportunities for developing their studentsôconceptual understandings. 
Traditional educational practices no longer provide pre-service teachers with the skills necessary to teach students to survive economically in todayôs workplace. Teachers must prepare their students to apply strategies for problem solving, and to use appropriate tools for learning, calculating, collaborating, and communicating. ICT competencies must be integrated into the curricular and pedagogical content presented, preparing teacher candidates to create the new learning environments. The curriculum for teacher educators is often rich with strategies for presenting subject matter and pedagogy; however, it may be lean in terms of integrating technological tools for supporting that learning. Consequently, curriculum developers for teacher preparation programmes must be vigilant in identifying appropriate ways to apply ICT tools throughout the coursework and experiences planned for pre-service teachers.

The most critical factor in the successful integration of ICTs into teacher education is the extent to which the teacher educators have the knowledge and skills for modelling the use of ICTs in their own teaching practices. To enable them to develop these skills requires a well-conceived and sustained programme of professional development. This section focuses on the professional development of teacher educators and the programmes for which they are responsible, such as pre-service programmes and certificates for practising teachers.

\section{Strategies Useful for CPD}

Countries that have initiated efforts to infuse ICTs into teacher education have found four professional development strategies helpful in successful technology integration. First, professional development needs to focus on teaching and learning rather than on hardware and software. It should be designed by first considering what student teachers are expected to know and be able to do in a specific discipline, and then infusing ICTs into the learning process so that acquiring the knowledge and skills is more efficient. Second, professional development is practically useless unless leaders and teacher educators are provided with access to technology resources and have the time and supportwhen needed $i ̈$ to apply the new knowledge and skills that they have learned. A just-in-time approach to professional development is a model that works well. In this approach, professional development is provided to teacher educators when they have a need or opportunity to use a specific technology tool or application to enhance learning. Third, professional development in the use of ICTs is not a one-time activity. To keep current with new developments means that professional development in ICTs must be an ongoing process. 
A further strategy for professional development is to start in a small way. Start by providing professional development in the use of ICTs to a small group of teaching staff. Perhaps this group will have volunteered or demonstrated that they have basic ICT competencies for personal use, or have expressed personal interest in using ICTs in their teaching. Working with this small group allows the professional development staff to determine the specific interests and needs of the teacher educators and what works best in the professional development process. Based on this experience, professional development may be provided to other small groups of faculty, thus expanding and refining the professional development efforts.

The opportunities for ICTs to create new paradigms of teaching and learning will depend largely on leadership and a shared vision, and on appropriate and continuing professional development. The planning and implementation of ICT-related professional development of teacher educators should be led by a planning group that includes representation and expertise from teacher educators, programme administrators, teachers, school administrators, technology experts, and business leaders. The diverse perspectives of the group should provide an understanding of the realities of the classroom, new views of the teaching-learning process, knowledge of the array of technologies that may be used to enhance learning, and community opinions.

An important aspect of professional development is not only enabling teacher educators to understand and use ICT tools in their teaching practices, but understanding how technology coupled with new approaches to teaching and learning, may enhance student learning. Many teacher educators recognize that approaches to education are changing and that new technology has the potential to improve education and student learning. They may also recognize the implications of increasing use of technology in society and employment, including employment directly related to their own disciplines and content areas. Less obvious are the implications for literacy and numeracy at the core of the educational process, and the need for teacher educators themselves to model good practice in their teaching so that their students can easily transfer these strategies into their own teaching practice. Teacher educators are experts in a domain, and it is important to respect this domain while helping them to revitalize and modernize their teaching with ICTs.

\section{Framework for CPD of Teachers in ICTs}

This study has recommended Teacher Knowledge Technological Pedagogical Content Knowledge (TPACK) as the framework for continuous professional development in ICTs. Teachers must consider the different knowledge domains 
they bring to the classroom that impact teaching and learning strategies they use and ways in which they choose to integrate technology into the classroom. Historically, teacher education has centred on content knowledge and pedagogy. Shulman (1986) provides an analysis of these components (pedagogical content knowledge) and stresses the importance of them working together rather than separately. Hughes supports him and adds technology as another component of knowledge that is needed by teachers. In 2006, other scholars, Mishra \& Koehler discussed in-depth the conceptual and theoretical framework of technological pedagogical content knowledge (TPACK). More research is still going on.

TPACK captures some of the essential qualities of knowledge required by teachers for ICT integration into classroom practice. Technological pedagogical content knowledge is an understanding that emerges from an interaction of content, pedagogy and technology knowledge. TPACK is the basis of effective teaching with technology and requires an understanding of the representation of concepts using technologies, pedagogical techniques that use technologies in constructive ways to each content; knowledge of what makes concepts difficult or easy to learn and how technology can help redress some of the problems; knowledge of student $\hat{Q}$ prior knowledge and theories of epistemology and knowledge of how technologies can be used to build on existing knowledge and to develop new epistemologies or strengthen old ones (Koehler \& Mishra, 2006).

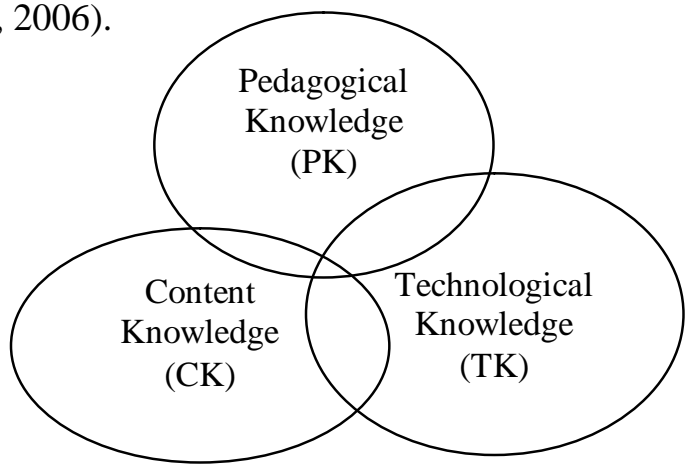

Figure 2: Technological Pedagogical Content Knowledge Model (TPACK)

Teachers require a combination of content, pedagogy and technology knowledge. The teachers must understand more than technology alone and more content alone. Teachers need to plan their lessons by using the Technology Integration Planning Model (TIP) for teachers. This model has six phases which outline a set of planning and implementation steps that help ensure that technology use will be meaningful, efficient and successful. 


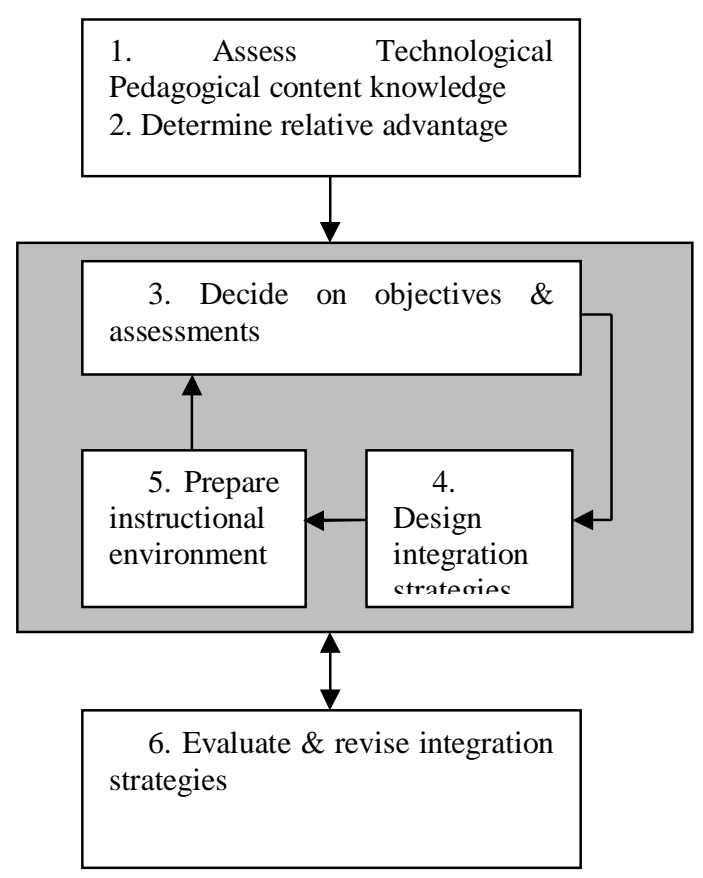

Figure 3: Technology Integration Planning Model

With the goal of enhancing a learning experience in a meaningful manner, technology integration follows a three-step process: planning the integration, implementing the integration and evaluating the integration. At each stage, several questions are asked. At the planning stage, the following questions are asked:

1. What are the goals of the current learning experience?

2. What is the content that learners need to learn?

3. Who are the target learners and what background knowledge and experiences do they have prior to the learning experience?

4. Are the learners motivated to learn this content?

5. How could learner motivation be increased and sustained?

6. What are the possible ways the learning could be experienced by the learners?

7. Where and under what condition should the learning experience occur?

At the implementation stage, the following questions are asked:

1. What are the potential types of technology most applicable to this learning situation?

2. What are the benefits and costs from selecting and using each of these potential technologies? 
3. What are the steps and sequence involved in the integration of ICTs within the specific learning experience?

4. Who will implement and monitor the use of technologies within the target learning experience?

Evaluation phase which determines the effectiveness of the technology integration of the technology integration has the following questions:

1. To what degree did the implemented ICT enhance the learning experience?

2. What procedures should be followed to evaluate the impact of the enhanced learning experience?

3. What types of feedback would help optimize use of the technology.

4. What key obstacles to integration need to be addressed/ overcome?

The rapid infusion of technology into schools requires a new generation of leaders who are able to use the new tools to enhance their own productivity and decision-making activities and who understand the importance of integrating technology into the learning process. Leadership is often the most important factor in the successful integration of ICTs into the schoolôs instructional practices and curriculum. Research has shown that without effective and supportive leadership, changes in the teaching-learning process and widespread, effective uses of technology in learning are not likely to occur.

\section{References}

Doering, A. H., Roblyer, M. D. (2010). Integrating Educational Technology into Teaching. Fifth Edition; Boston: Pearson.

Fullan, M. \& Hangreaves, A. (1992). Teacher development and educational change. London: The Falmer Press.

ISTE (2007). National Educational Technology Standards for Students. Available at: www.iste.org.

Koehler, M. J., Mishra, P. (2008). Introducing Technological Pedagogical Content Knowledge. In AACTE Committee on Innovation and Technology. The Handbook of Technological Pedagogical Content Knowledge for Educators. Hillsdale, NJ; Lawrence Erbaum Associates.

Otunga, R. N., Odero, I. I. \& Barasa, P. L. (2011). A handbook for curriculum and instruction. Eldoret: Moi University Press.

Shulman L. S. (1986). Those who understand: Knowledge growth in Teaching. Educational Researcher, 15(2) 4-14. 
Society for Information Technology and Teacher Education. 2002. Basic Principles in Technology - Curriculum - Cost - Evaluation. Available at http://www.aace.org/site. 
